\title{
Feeding Efficiency in the Cave Salamander Haideotriton wallacei
}

by

\author{
STEWART B. PECK*
}

\section{INTRODUCTION}

Cave adapted anirnals often exhibit bizarre morphologies. A question of interest to students of evolutionary biology concerns the selective pressures which have led to these morphological modifications. It is assumed from the frequency of convergence of "cave modifications" that they have an adaptive value for cave life. Poulson (1964) and Mitchell (1969) discuss the hypothesis and the literature that scarcity of food in caves may act as a forceful selective agent. The selection favors increased feeding and metabolic efficiency. The morphological changes result from this selection.

Among the vertebrates, the American Amblyopsid cave fishes have been investigated (Poulson, 1963) and show increasing feeding and metabolic efficiency in conjunction with increased morphological specialization. There exists an even richer array of cave salamander species. Little has been reported on them beyond their morphology and taxonomy (Poulson, 1964). However, they present many opportunities to investigate several aspects of the physiology and ecology of cave adaption and evolution. Brandon (1971) has reviewed aspects of morphological modification of North American troglobitic salamanders.

Lee (1969) has reported on the feeding habits of the Georgia Blind Salamander, Haideotriton wallacei Carr. I would like to supplement his findings and to report an additional interpretation of the results.

\section{METHODS}

In September, 1968, eight specimens (20-26 mm snout to vent length) of $H$. wallacei were captured in Gerard's Cave, Jackson County, Florida. The specimens were killed within one hour of capture in Chloretone, fixed for 12 hours in $4 \%$ formalin, and preserved in $70 \%$ ethyl alcohol. The entire digestive tract of each salamander was later examined in the laboratory.

* Department of Biology, Carlton University Ottawa, Ontario, Canada. 


\section{OBSERVATIONS}

The food items were 3 amphipods (Crangonyx floridanus, 2-3 $\mathrm{mm}$ in length), 4 copepods (Macrocyclops albidus, $1 \mathrm{~mm}$ in length), and 12 unidentified ostracods (1 $\mathrm{mm}$ in length). All salamanders contained food boluses and all but one individual contained boluses of silt. The data are presented in Table 1. Some of the food was associated with silt which was probably sucked into the mouth while feeding with the snapping motion described by Pylka and Warren (1958). Other boluses contained only silt and debris, with no material identifiable as food items. The silt and debris boluses may represent either unsuccessful feeding attempts, or feeding upon easily digested organisms such as small freshwater oligochaete worms. The silt boluses probably do not represent intentional ingestion of silt for its nutritional value as suggested by Lee (1969), because this would be strange behavior for a generally predatory group like salamanders. However, this question is an interesting one that could represent a new mode of salamander feeding in a food poor habitat.

In observations of a living Haidotriton kept at Harvard in water at $22^{\circ} \mathrm{C}$ (the natural cave water is $20^{\circ} \mathrm{C}$ ), food items ( $3 \mathrm{~mm}$ long Hyallela amphipods) were voided 24-72 hours after ingestion. This suggestes the food boluses found in the dissections were ingested 1-3 days before preservation. No indication of parasitic worms was seen in the digestive tracts or body cavities.

Table 1. Gut contents of eight specimens of Haideotriton wallacei collected in Gerard's Cave, Jackson County, Florida.

Specimen length (mm, snout to vent)

$\begin{array}{lcccccccc} & 26 & 26 & 25 & 24 & 23 & 22 & 22 & 20 \\ \text { Item } & & & & & & & 1 & 1 \\ \text { Amphipod } & & 1 & & & & & 1 & 3 \\ \text { Ostracod } & 4 & 1 & 1 & 1 & 1 & & 1 & \\ \text { Copepod } & & & & & 1 & 2 & 1 & \mathrm{x} \\ \text { Silt-debris } & & \mathrm{x} & \mathrm{x} & \mathrm{x} & \mathrm{x} & \mathrm{x} & \mathrm{x} & \mathrm{x}\end{array}$

\section{DISCUSSION AND INTERPRETATION}

Food and non-food boluses occured at varying distances along the digestive tract. The numbers of these two types of boluses yield inferences on the animals' efficiency in locating and capturing food in an environment devoid of light and visual cues. The digestive tracts of the specimens held a total of 21 separated boluses. These are assumed to record a minimum of 21 feeding attempts. Seven boluses did not contain recognizable food and may represent unsuccessful feeding attempts. These figures thus suggest that Haideotriton has the ability to sense food and capture it in at least 14 out of at least $21(67 \%)$ of its feeding attempts in a natural environment. 


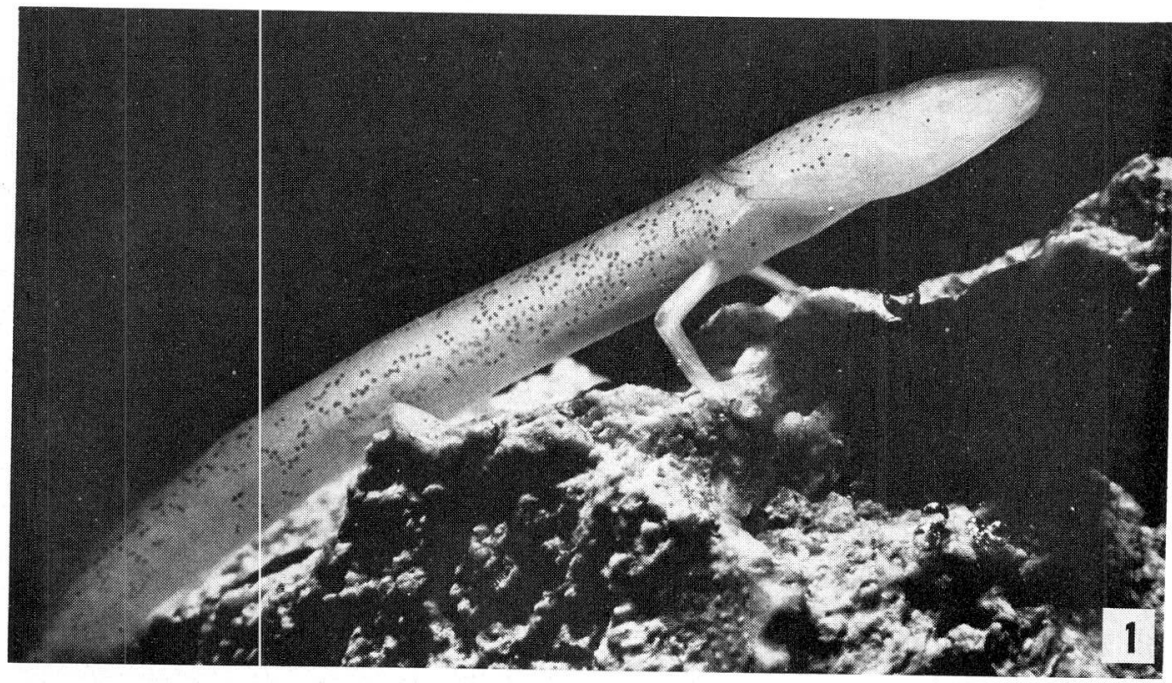

Fig. 1. Side view of $20 \mathrm{~mm}$ (snout to vent) long Haideotriton wallacei, showing the attenuated limbs and how the head is held above the substrate. Eye vestiges are not visible.

Of course, in arriving at the above figure, several assumptions must be made. The first is that one feeding attempt is observable as one bolus. Another is that a food item is not divided into more than one bolus which will be observed at different distances along the digestive tract. Another is that the salamanders do not snap open the mouth and injest silt without first detecting a food item. All these seem to be reasonable assumptions based on my observations of a live Haideotriton.

The small sample size I used is a source of unreliability. However, this cannot be avoided when trying to recover as much information as is possible from collections of rare animals. Lee (1969) had a larger sample size but unfortunately he did not present his data in a way that allows the calculation of feeding efficiency. Future studies of the contents of the digestive tracts of rare troglobitic salamanders should include an attempt to recover data on the boluses that can help in calculating feeding efficiencies.

Several morphological features such as eye and pigment reductions and metamorphosis avoidance in troglobitic salamanders have been interpreted as the result of selection operating in the interest of energy economy (Brandon, 1971). Likewise, selection can favor more efficient feeding movements through the production of a broader head with a wider mouth gape. Also, a greater food detection efficiency for searching a greater area per unit of energy expended is gained by raising the body and head above the substrate, partially through limb attenuation (Fig. 1) (Poulson, 1964; and Brandon, 1971).

In this mode of thinking it is reasonable to assume that these morphological modifications, found in $H$. wallacei, should help it to achieve a greater feeding efficiency than that of a non-modified aquatic salamander feeding in the dark. At 


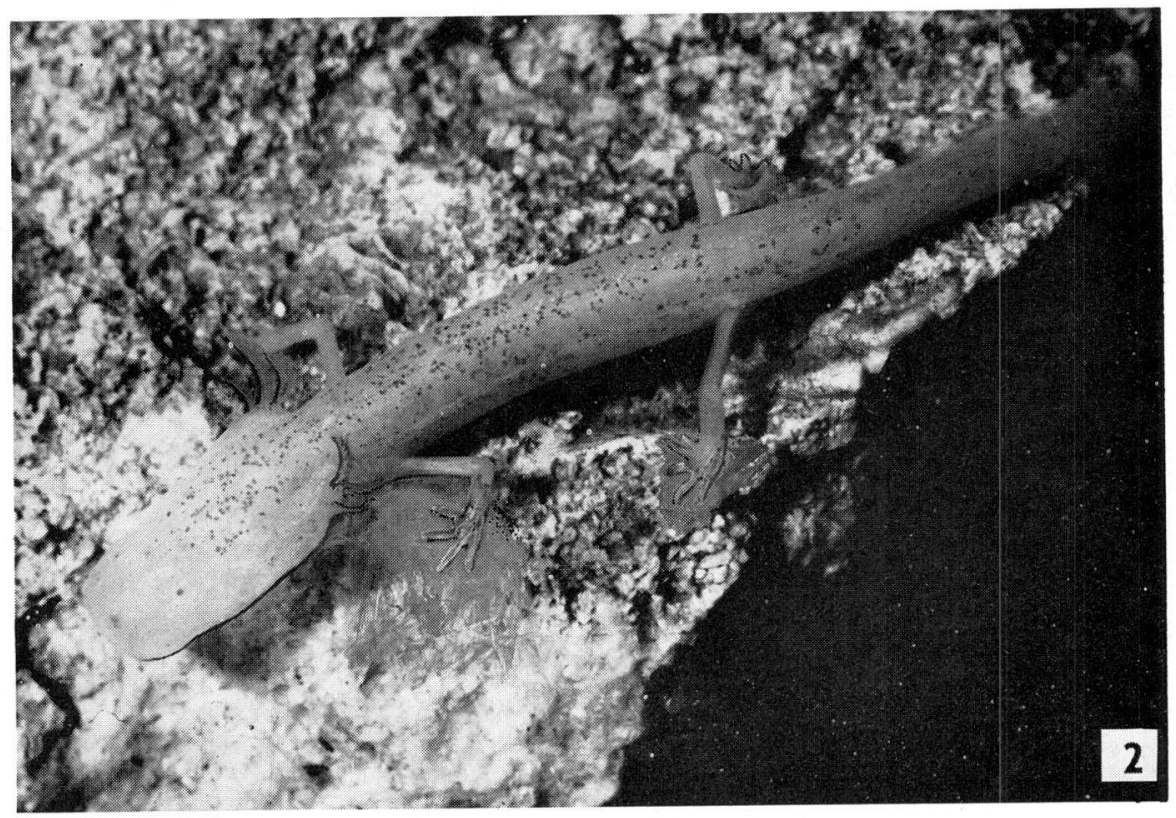

Fig. 2. Dorsal view of $20 \mathrm{~mm} \mathrm{H}$. wallacei, showing chromatophores and eye vestiges.

present there is no data on feeding efficiencies for other salamanders in dark, aquatic habitats to compare with the calculated figure of $67 \%$ success in $H$. wallacei.

\section{RECOMMENDATIONS}

I strongly urge that future studies on troglobitic and troglophilic salamander feeding habits extract as much data as possible from digestive tract dissections. Of course the number of dissections must be limited in species known from few specimens. A more rewarding approach to this problem of comperative feeding behavior and efficiency will come from observations of living salamanders in controlled laboratory conditions. Past studies of feeding in cave-dwelling salamanders (Smith, 1948; Brandon, 1967; Lee, 1969) have emphasized what the salamanders ate (which may be whatever is available in a particular size range). Of equal if not greater importance is how successful they are at capturing the food. Only then can we gain the experimental background information needed to apply to the questions of food scarcity, energy economy, and feeding efficiency in the evolutionary biology of cave salamanders in particular, and cave predators in general.

In my laboratory we are presently attempting to gain this and other data for the terrestrial troglophilic salamander Eurycea lucifuga. Hopefully, others will take up work on other pieces of these questions. 


\section{ACKNOWLEDGEMENTS}

Professors David Culver, John Cooper, and Ernest Williams are thanked for their comments of various drafts of the manuscript. Dr. John Holsinger, Old Dominion College, Norfolk, Virginia, and Dr. Andrew Weaver, College of Wooster, Wooster, Ohio are thanked for identifying respectively the amphipods and copepods. Collections and observations were made while conducting field work partially supported by Evolutionary 33iology Training Grant GB 7346, Prof. Reed C. Rollins, principal investigator, Harvard University.

\section{SUMMARY}

Selection for efficiency in food capture may be a dominant influence in the evolutionary biology of predaceous cave animals. A sample of 8 Haideotriton wallace $i$ from a natural population contained 21 feeding boluses in their digestive tracts. Fourteen of these boluses contained food, demonstrating success in at least $67 \%$ of the feeding attempts.

\section{RÉSUMÉ}

L'efficacité de la prise de nourriture peut avoir une influence dominante et sélective sur la biologie évolutive des animaux cavernicoles prédateurs.

La dissection des tubes digestifs de 8 Haideotriton wallacei prélevés dans une population naturelle contenaient 21 bols alimentaires. Quatorze de ceux-ci renfermaient des élémerits nutritifs, ce qui démontre, à $67 \%$ au moins, la réussite des tentatives d'alimentation faites par les animaux examinés.

\section{REFERENCES}

BRANDON, R.A. - 1967 - Food and an intestinal parasite of the troglobitic salamander Gyrinophilu's palleucus necturoides. Herpetologica, 23 (1): 52-53.

BRANDON, R.A. - 1971 - North American troglobitic salamanders: some aspects of modification in cave habitats, with special reference te Gyrinophilus palleucus. Bull. Nat. Speleo. Soc., 33:1-21.

LEE, D.S. - 1969 - A food study of the Salamander Haideotriton wallacei Carr. Herpetologica, 25 (3): 175-177.

MITCHELL, R.W. - 1969 - A comparison of temperate and tropical cave communities. Southw. Nat., 14 (1): 73-88. POULSON, T.L. - 1963 - Cave Adaption in Amblyopsid Fishes. Am. Mid. Nat., 70 (2):
257-290.

POULSON, T.L. - 1964 - Animals in aquatic environments: animals in caves. Handbook of Physiology: Adaption to the environment, ch. 47: 749-771.

PYLKA, J.M. and R.I). WARREN - 1958 - A population of Haideotriton in Florida. Copeia, 1958 (4): $334-336$.

SMITH, P.W. - 1948 - Food habits of cave dwelling amphibians. Herpetologica, 4: 205-208. 